\title{
PEMBUATAN INFORMASI GEOSPASIAL SARANA DAN PRASARANA KELURAHAN WATES KABUPATEN KULON PROGO PADA SKALA 1:15.000
}

\author{
Rochmad Muryamto $^{1^{*}}$, Waljiyanto ${ }^{2}$, M. Iqbal Taftazani ${ }^{3}$, Ruli Andaru ${ }^{4}$, Untung \\ Rahardjo $^{5}$, Gondang Riyadi ${ }^{6}$, Wahyu Marta $M^{7}$., Annisa Farida H. ${ }^{8}$, Anindya \\ Sricandra P. ${ }^{9}$, Ni Putu Praja C. ${ }^{10}$
}

1,2,3,4,5,6,7,8,9,10 Program Studi Teknik Geomatika, Departemen Teknologi Kebumian Sekolah Vokasi, Universitas Gadjah Mada

*rochmad_mury@ugm.ac.id

\begin{abstract}
ABSTRAK
Field Research Center (FRC) merupakan bagian dari program Teaching Industry Sekolah Vokasi Universitas Gadjah Mada. FRC dibangun bertujuan untuk mengembangkan hasil penelitian dan pengabdian agar menjadi sebuah produk yang dapat dimanfaatkan oleh masyarakat serta mendekatkan mahasiswa pada obyek materi pembelajaran agar menjadi lulusan yang siap bekerja. Rencana FRC akan dibangun di atas tanah seluas 6,5 hektar di Kelurahan Wates, Kabupaten Kulon Progo. Di sekitar lokasi pembangunan FRC, terdiri atas kawasan penyangga seluas 29 hektar. Kawasan penyangganya terdiri atas berbagai berbagai sarana dan prasarana, seperti sarana pendidikan, kesehatan, pertahanan dan keamanan, jalan, sungai, rel kereta api, dan lain sebagainya. Penelitian ini bertujuan untuk menyajikan informasi geospasial sarana dan prasarana yang berada di sekitar lokasi FRC. Data yang digunakan dalam penelitian ini terdiri atas data citra foto udara dan hasil dijitasi. Data citra foto udara diambil dengan menggunakan wahana pesawat tanpa awak (UAV) dengan tinggi terbang 270 meter dan ketelitian 0,775 pix. Data vektor yang dihasilkan dari proses dijitasi on-screen terdiri atas unsur geospasial bangunan (geometri poligon dan titik), jalan (geometri poligon), sungai (geometri poligon), drainase (geometri garis), rel kereta api (geometri garis), dan batas administrasi kelurahan (geometri garis). Masing-masing unsur geospasial disertai dengan data atribut yang diperoleh dari hasil survei lapangan. Sistem informasi geospasial sarana dan prasarana disajikan dalam skala 1:15.000. Sistem informasi geospasial ini diharapkan dapat membantu Kelurahan Wates dalam mengembangkan sarana prasarana yang terdapat pada sekitar lokasi FRC.
\end{abstract}

Kata Kunci: Field Research Center, sistem informasi geospasial, sarana prasarana, sekolah vokasi

\begin{abstract}
Field Research Center (FRC) is part of Teaching Industry program of Vocational School. FRC was build to develop research and service result into products. The products utilized by the community and bring students closer to learning material objects in order to become graduates who are ready to work. FRC will be build on 6.5 hectares of land in Kelurahan Wates, Kulon Progo Regency. Around the location of the FRC construction consists of a 29 hectare supporting area. The supporting area consists of various facilities and infrastructure, such as education, health, defense and security facilities, roads, rivers, railroads, and so on. This study aims to present geospatial information for infrastructure around the FRC location. The data used in this study consisted of aerial photo image data and results of digitization. Aerial photo image data taken using a drone vehicle (UAV) with a height of 270 meters and accuracy of 0.775 pix. Vector data generated from digitizing on-screen process. These are consists of six geospatial elements, such as building (polygon geometry and dots), roads (polygon geometry), rivers (polygon geometry), drainage (line geometry), railroad tracks (line geometry), and boundaries village administration (line geometry). Each geospatial element accompanied by attribute data that obtained from field surveys. Geospatial information about infrastructure presented on big scale of 1: 15,000. This geospatial information expected to help Kelurahan Wates developing infrastructure around the FRC location.
\end{abstract}

Keywords: Field Research Center, geospatial information system, infrastructures, vocational school 


\section{PENDAHULUAN}

Kelurahan Wates merupakan salah satu kelurahan yang ada di Kabupaten Kulon Progo. Pada awal berdiri, sistem pemerintahan Kelurahan Wates didefinisikan sebagai desa. Seiring perkembangan jaman dan mempertimbangkan peran Kelurahan Wates terhadap perkembangan Kabupaten Kulon Progo, maka sistem pemerintahannya diubah menjadi kelurahan pada tanggal 1 Desember 2010. Dasar hokum tentang perubahan dari Desa Wates menjadi Kelurahan Wates diatur dalam Peraturan Daerah Kabupaten Kulon Progo Nomor 16 Tahun 2008 tentang Perubahan Status Desa Wates Menjadi Kelurahan Wates, sebagaimana telah diubah dengan Peraturan Daerah Kabupaten Kulon Progo Nomor 9 Tahun
2009 tentang Perubahan Atas Peraturan Daerah Kabupaten Kulon Progo Nomor 16 Tahun 2008 tentang Perubahan Status Desa Wates Menjadi Kelurahan Wates (www.kelurahanwates.kulonprogokab.go. id).

Kelurahan Wates memiliki luas wilayah 428,2422 hektar. Secara geospasial, Kelurahan Wates berada di Kecamatan Wates. Kelurahan Wates berbatasan dengan Desa Pengasih di sebelah utara, sebelah timur adalah Desa Pengasih dan Desa Margosari, sebelah selatan adalah Desa Giripeni dan Desa Triharjo, dan sebelah barat adalah Desa Karangsari. Peta Kelurahan Wates disajikan pada Gambar 1.

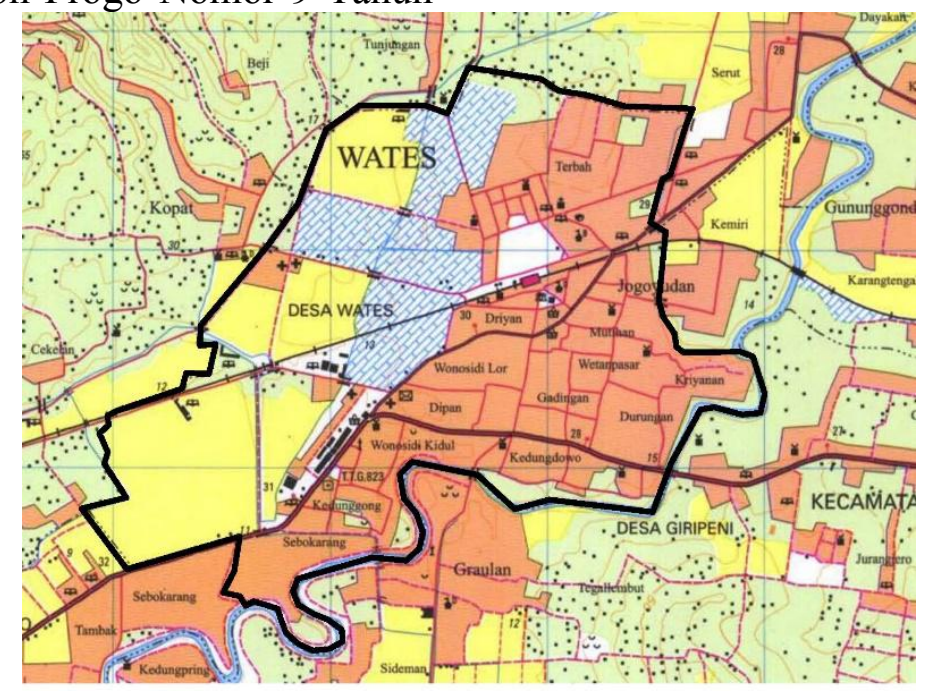

Gambar 1. Peta Kelurahan Wates (sumber Peta RBI Wates, 1999)

Kelurahan Wates berada di pusat Ibukota Kabupaten Kulon Progo, sehingga di Kelurahan Wates banyak aktvitas mulai dari aktivitas pemerintahan, perdagangan, pendidikan, dan lain sebagainya. Mempertimbangkan banyaknya aktivitas yang terjadi di Kelurahan Wates, maka perlu adanya sarana prasarana yang baik. Dalam LKjIP Kelurahan Wates tahun 2016 serta Renja 2017 menyebutkan bahwa Kelurahan Wates belum memiliki sarana dan prasarana yang cukup memadai untuk mendukung berbagai aktivitas masyarakat. Hal tersebut disebabkan karena sumber dana yang diperoleh masih minim, sehingga alokasi penganggaran untuk pembangunan sarana prasarana belum memadai. Adanya keterbatasan dana yang diterima oleh Kelurahan Wates menyebabkan beberapa rencana kegiatan pengembangan kelurahan tidak dimasukkan dalam rencana kegiatan, seperti misalnya pengadaan data geospasial tidak muncul dalam Renja 2017. Berdasarkan hal tersebut, mendorong peneliti di perguruan tinggi melaksanakan kegiatan pengabdian masyarakat di Kelurahan Wates untuk memproduksi informasi geospasial terkait sarana prasarana. Hasil kegiatan pengabdian masyarakat ini diharapkan 
dapat membantu pemerintah Kelurahan

Wates untuk pengambilan keputusan dalam pembangunan dan pengembangan sarana prasana yang lebih memadai.

Data dan informasi geospasial memiliki peran penting dalam perencanaan pembangunan sarana prasarana di Kelurahan Wates. Melalui informasi geospasial, pemerintah kelurahan dapat mengetahui lokasi dan jenis sarana prasarana yang ada di Kelurahan Wates berdasarkan kategorinya. Selain itu, data atribut yang berisi informasi mengenai jumlah sarana prasarana dapat membantu pemerintah untuk menambahkan jenis sarana prasarana agar memadai kebutuhan masyarakat. Adanya data dan informasi geospasial dapat mendukung keberlangsungan dan keberlanjutan visi Kelurahan Wates yaitu "Terwujudnya Penyelenggaraan Pelayanan Pemerintahan yang Prima."
METODE

Kegiatan pembuatan informasi geospasial sarana prasarana terdiri atas beberapa tahapan. Sebelum dilakukan pengambilan data di Kelurahan Wates, terlebih dahulu dilakukan survei pendahuluan berupa permohonan ijin dan pemaparan tentang pentingnya data serta informasi geospasial pada pemerintah Kelurahan Wates. Survei pendahuluan bertujuan untuk menjelaskan tujuan kegiatan pengabdian masyarakat dan penelitian serta detail kegiatan yang akan dilaksanakan.

Pelaksanaan pembuatan informasi geospasial di Kelurahan Wates perlu didukung dengan beberapa bahan dan alat. Adapun bahan yang diperlukan dalam kegiatan pembuatan informasi mozaik foto udara yang telah tergeorefensi. Sedangkan perangkat yang diperlukan adalah perangkat lunak SIG, komputer/ laptop, dan printer.

Tahapan pembuatan informasi geospasial sarana prasarana disajikan pada diagaram alir berikut.

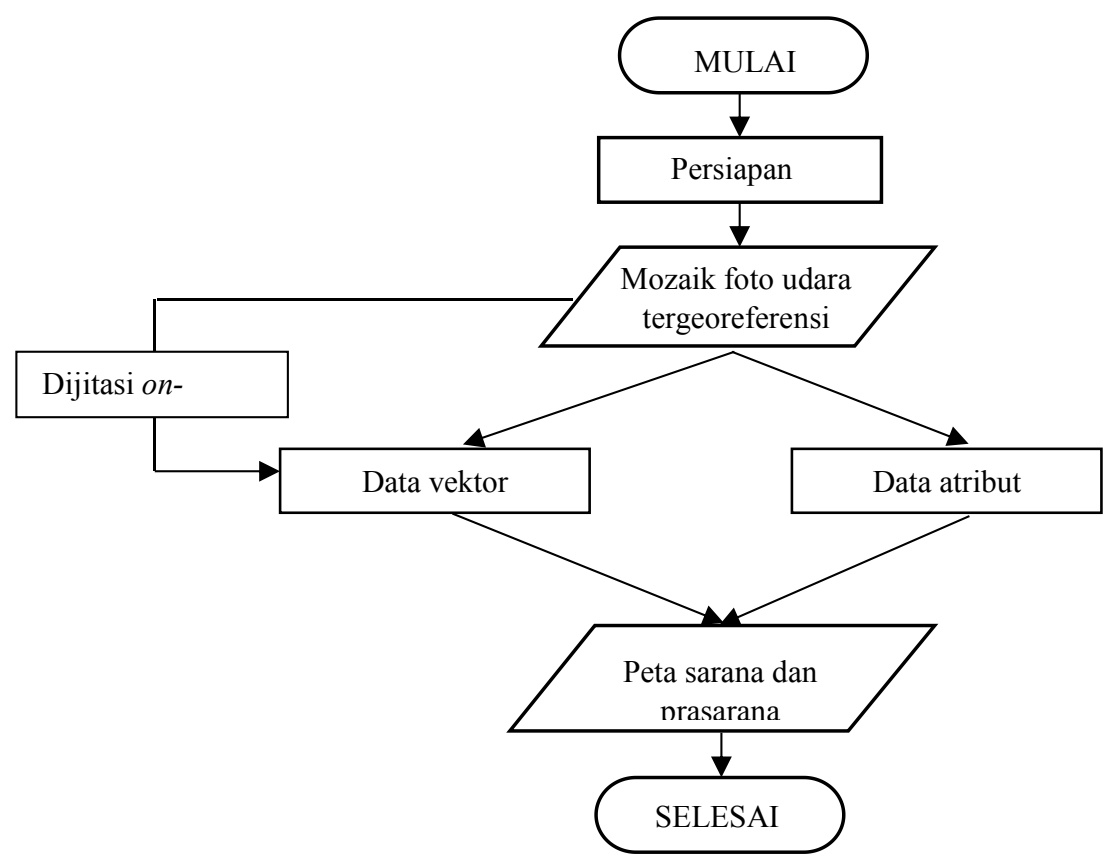

Gambar 2. Diagram alir pelaksanaan pembuatan informasi geospasial sarana prasarana 
Uraian penjelasan tahapan pengabdian masyarakat disajikan sebagai berikut:

1. Survei pendahuluan untuk melihat lokasi dan ijin pada Kelurahan Wates dilakukan untuk perijinan pengumpulan data atribut yang ada di Kelurahan Wates.

2. Tahap persiapan alat dan bahan terdiri atas persiapan pengumpulan data yaitu mozaik foto udara dan perangkat lunak SIG (Sistem Informasi Geospasial).

3. Proses dijitasi on-screen terhadap obyek bangunan, jalan, saluran, dan sungai yang ada pada mozaik foto udara dilakukan menggunakan perangkat lunak SIG untuk membuat data vektor.
4. Tahap selanjutnya dilakukan pengumpulan dan pemasukan data atribut yang telah diperoleh dari survei lapangan.

5. Informasi geospasial dibuat layoutnya dan disajikan dalam skala mulai 1:1000 s/d 1:5000.

6. Selanjutnya dilakukan konsultasi kepada aparat kelurahan dan/atau masyarakat untuk meminta masukan terkait peta yang dibuat.

7. Serah terima peta foto, jika peta foto telah selesai dibuat.

\section{HASIL DAN PEMBAHASAN}

Kegiatan pengabdian masyarakat di Kelurahan Wates ini menghasilkan informasi geospasial skala besar yaitu 1:15000. Berikut adalah informasi geospasial Kelurahan Wates.

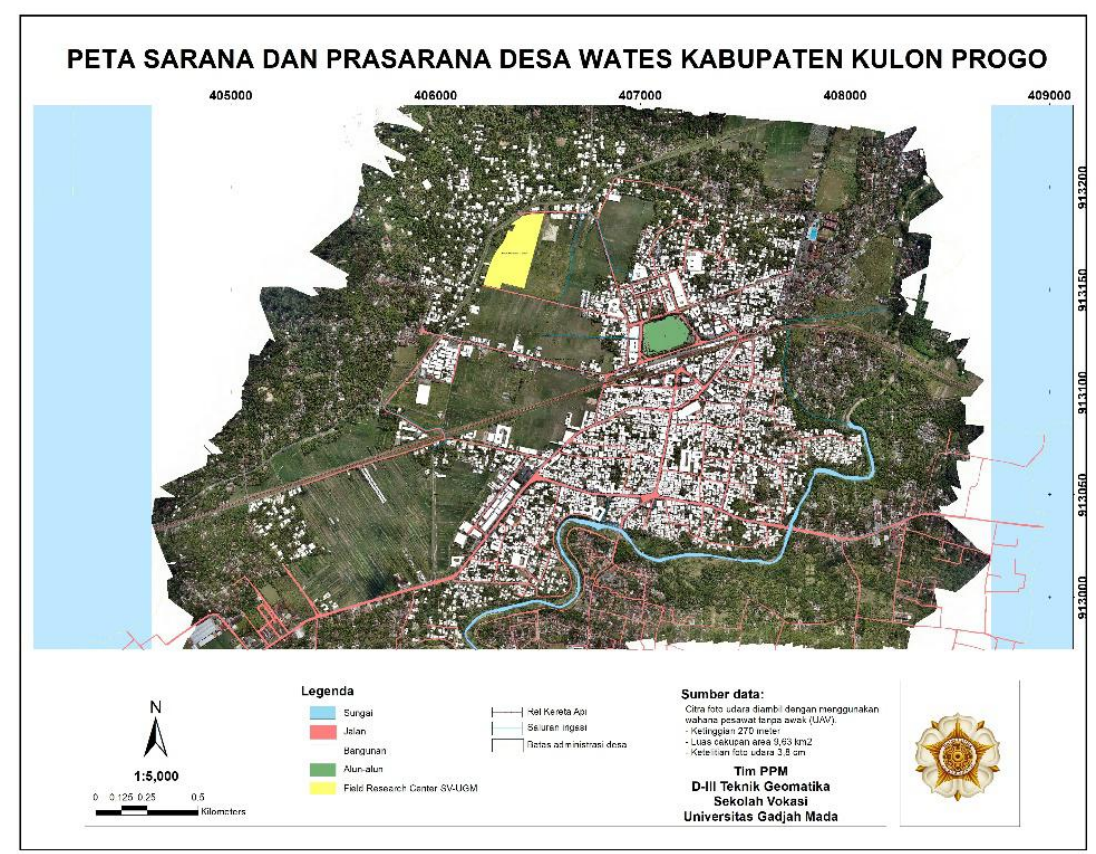

Gambar 3. Informasi geospasial sarana dan prasarana Kelurahan Wates

Data yang digunakan untuk membangun informasi geospasial sarana prasarana pada kegiatan ini adalah mozaik foto udara yang pengambilan datanya menggunakan wahana pesawat tanpa awak dengan ketinggian $270 \mathrm{~m}$ dan ketelitian $3,8 \mathrm{~cm}$. Berdasarkan mozaik foto udara tersebut, dilakukan dijitasi secara on-screen. Unsur geospasial yang didijitasi terdiri atas bangunan, jalan, sungai, saluran irigasi, rel kereta api, batas administrasi desa. Proses dijitasi on-screen dilakukan dengan menggunakan perangkat lunak ArcGIS. 
Tabel 1. Unsur geospasial dan tipe geometrinya

\begin{tabular}{lll}
\hline \multicolumn{1}{c}{ Unsur geospasial } & \multicolumn{1}{c}{ Tipe geometri } & \multicolumn{1}{c}{ Warna } \\
\hline \multirow{2}{*}{ Bangunan } & Titik & Hijau \\
\cline { 2 - 3 } & Polygon & Putih \\
\cline { 2 - 3 } Jalan & Poligon & Pink \\
\cline { 2 - 3 } Sungai & Polik & Biru tua \\
\cline { 2 - 3 } & Titik & Biru muda \\
\hline Saluran irigasi & Garis & Biru tua \\
\hline Rel kereta api & Garis & Biru tua \\
\hline Batas administrasi desa & Garis & Merah tua \\
\hline
\end{tabular}

Unsur bangunan, jalan, dan sungai didijitasi dengan menggunakan dua tipe geometri, yaitu tipe geometri poligon dan titik. Tipe geometri poligon digunakan untuk menyajikan bentuk unsur geospasial seperti bentuk nyata pada citra foto udara karena hasil dari kegiatan ini adalah sistem informasi geospasial sarana prasarana dalam skala besar. Tipe geometri titik digunakan untuk menyajikan informasi lokasi pengambilan data. Apabila ditampilkan secara bersama antara tipe geometri polygon dan titik, maka di atas unsur geospasial terdapat informasi tambahan.

Unsur-unsur geospasial sarana prasarana di Kelurahan Wates Kabupaten Kulon Progo disimpan dalam geodatabase yang dibangun dalam ArcCatalog. Pembangunan geodatabase dan layerisasi dilakukan sebelum dilakukan proses dijitasi on-screen .

\section{SIMPULAN}

Berdasarkan beberapa detail kegiatan pengabdian masyarakat yang telah diuraikan di atas dapat diambil kesimpulan dan beberapa saran. Kegiatan pengabdian masyarakat telah menghasilkan informasi geospasial yang berisi informasi tentang sarana prarana yang ada di Kelurahan Wates. Informasi geospasial yang telah dibangun diharapkan dapat membantu pemerintah Kelurahan Wates dalam pengambilan keputusan berbasis spasial untuk membangun sarana prasarana yang memadai.

Kedepannya, data geospasial yang telah ada dapat diperbarui secara berkala dan secara partisipatif. Sistem informasi geografis yang telah dibangun dapat dikembangkan menjadi Sistem Informasi Geospasial (SIG) berbasis website. Pengembangan SIG berbasis web dapat dimanfaatkan untuk kegiatan berbagi pakai data geospasial, sehingga data dan informasi geospasial dapat dimanfaatkan oleh instansi lainnya dan Pemerintah Kabupaten Kulon Progo untuk berbagai keperluan pengambilan keputusan.

\section{DAFTAR PUSTAKA}

--, 2018, Profil Kelurahan Wates, dalam www.kelurahanwates.kulonprogoka b.go.id, akses tanggal 10 Maret 2018 .

Bakosurtanal, 1999, Peta RBI Digital 1:25.000 Lembar 1408-214 Wates, Badan Koordinasi Survei dan Pemetaan Nasional, Cibinong, Bogor

Baldridge, J. (2012). ArcGIS 10: What is a Geodatabase? Retrieved from http://helpwiki.evergreen.edu/wiki/i ndex.php/ArcGIS_10: What is_a Geodatabase $\% 3 \mathrm{~F}$

Bueno, M. do C. D. (2011). Spatial Data: Use and Dissemination.

Kelurahan Wates, 2016, Laporan Kinerja Instansi Pemerintah Tahun 2016 (LKjIP), Kelurahan Wates, Kulon Pprogo

Kelurahan Wates, 2016, Rencana Kerja Tahun 2017, Kelurahan Wates, Kabupaten Kulon Progo 